\title{
Thoracic ultrasound assessment of lung consolidation at weaning in Holstein dairy heifers: Reproductive performance and survival
}

\author{
A. G. V. Teixeira, J. A. A. McArt, and R. C. Bicalho ${ }^{1}$ \\ Department of Population Medicine and Diagnostic Sciences, College of Veterinary Medicine, Cornell University, Ithaca, NY 14850
}

\begin{abstract}
The objective of this study was to determine the association of lung consolidation at weaning with later reproductive performance and survival. Ultrasonography of the lungs was performed at $60 \mathrm{~d}$ of life in recently weaned Holstein heifer calves from a single farm in New York State. Thoracic screening covered the right 2nd through 10th and left 3rd through 9th intercostal spaces and was performed using a $6.2-\mathrm{MHz}$ linear transducer. Each calf was classified as not having lung consolidation (hyperechoic line with reverberation artifact with or without comet tail) or with lung consolidation (any detectable heterogeneous hypoechoic area). A total of 613 heifer calves were enrolled in the study, with 489 $(79.8 \%)$ classified as not having lung consolidation and $124(20.2 \%)$ classified as having lung consolidation. No difference in mortality was observed from 60 to $350 \mathrm{~d}$ of life between heifers with lung consolidation (1.6\%) and without lung consolidation (2.0\%). Six hundred and one nulliparous Holsteins became eligible for insemination at $350 \mathrm{~d}$ of life; the hazard of being removed from the herd between $350 \mathrm{~d}$ of life and first calving for heifers with lung consolidation at weaning was higher (hazard ratio $=4.7,95 \%$ confidence interval $=2.1$ to 10.7 ). Additionally, heifers without lung consolidation tended to have improved pregnancy to first artificial insemination (62.0\%) compared with heifers with lung consolidation $(52.5 \%)$. Overall reproductive performance was also affected as heifers with lung consolidation at $60 \mathrm{~d}$ of life had a lower hazard of pregnancy compared with those without lung consolidation (hazard ratio $=0.7,95 \%$ confidence interval $=0.6$ to 0.8 ). From 601 animals that entered the breeding period, 565 entered the milking herd and were followed during the first 3 mo of lactation. No differences in weekly average milk production were observed between animals with or without lung consolidation at weaning. Our results show
\end{abstract}

Received September 19, 2016.

Accepted January 2, 2017.

${ }^{1}$ Corresponding author: rcb28@cornell.edu that heifers with lung consolidation at weaning were less likely to get pregnant and more likely to be culled before their first parturition than heifers without lung consolidation; this difference did not continue into first lactation milk production, risk of culling, or reproductive performance.

Key words: dairy calves, ultrasonography, lung consolidation, reproduction

\section{INTRODUCTION}

Bovine respiratory disease (BRD) affects approximately $16 \%$ of preweaned heifers in the United States, of which $90.2 \%$ of BRD affected preweaned heifers are treated with antibiotic (USDA, 2012), leading to impaired survival and reproductive performance (Stanton et al., 2012). Currently, no gold standard is available for $\mathrm{BRD}$ diagnosis, and researchers have developed 2 useful respiratory scoring charts to assist with detection and treatment of BRD (McGuirk, 2008; Love et al., 2014). In addition to these subjective measures, thoracic ultrasound has been proposed as a useful calf-side tool to improve quantitative diagnosis of BRD (Buczinski et al., 2013, 2014). Studies assessing the sensitivity and specificity of thoracic ultrasound in diagnosing BRD, where BRD was confirmed by necropsy, reported a sensitivity of 86 to $94 \%$ and a specificity of 98 to $100 \%$ (Rabeling et al., 1998; Ollivett et al., 2015). It is important to note that the Rabeling study only evaluated clinical cases and the Ollivett study had a small number of animals. Thoracic ultrasound has been proposed as a calf-side tool to aid BRD diagnosis, detect pulmonary lesions, and reduce use of antimicrobials (Jung and Bostedt, 2004; Ollivett et al., 2011).

The extent to which lung lesions, confirmed at slaughter, can impair subsequent productivity has been assessed by multiple studies in the feedlot cattle. These studies found lower weight gain during feeding, a high incidence and lower weight gain in subclinical (never diagnosed or treated) BRD animals, and economic losses ranging from $\$ 1.79$ per animal entering the feedlot, to approximately $\$ 54$ for animals presenting lesions at slaughter and recurrent BRD treatments (Thompson 
et al., 2006; Schneider et al., 2009). In contrast, results regarding the effects of pulmonary lesions on milk production and reproductive performance of dairy animals are scarce. To our knowledge, only one study has been conducted that correlates lung lesions in dairy cattle with performance (Adams and Buczinski, 2016). In this study, lung consolidation was assessed using thoracic ultrasonography in 3-mo-old Jersey heifers. Adams and Buczinski (2016) reported that heifers with extensive consolidation had a higher risk of being removed from the herd between 80 and $330 \mathrm{~d}$ of life but did not find a significant effect of lung score to age at first calving. Although few studies have evaluated pulmonary lesions, more have reported detrimental effects of early life diagnosis of BRD on performance through the first lactation, higher risk of herd removal, and delayed age at first calving (Bach, 2011; Stanton et al., 2012).

Given the limited knowledge surrounding pulmonary lesions in dairy heifers and their association with production outcomes, our objective was to explore the consequences of lung consolidation in dairy heifers at weaning with subsequent survival and reproductive performance. For this prospective cohort study, we hypothesized that heifer calves with lung consolidation at weaning would have higher age at pregnancy and a higher culling risk when compared with herd mates without lung consolidation. A secondary objective was to investigate the association of lung consolidation at weaning with weekly milk average, risk of culling, and risk of pregnancy to first service within the first 3 mo of first lactation.

\section{MATERIALS AND METHODS}

The study was conducted on a commercial dairy farm located near Ithaca, New York, from November 2013 until February 2014. The study was approved by the Institutional Animal Care and Use Committee of Cornell University (protocol number 2013-0076).

\section{Preweaning Management}

This study was conducted in a commercial dairy farm milking approximately 3,700 Holstein cows, near Ithaca, New York. Newborn Holstein dairy heifers were fed $4 \mathrm{~L}$ of pooled pasteurized colostrum via esophageal tube within $4 \mathrm{~h}$ after birth and moved daily from the maternity pen to the preweaning calf barn. Preweaning heifers were housed in a green-house type barn with positive ventilation composed of 10 identical group pens $\left(85 \mathrm{~m}^{2}\right)$ bedded with straw. Twenty-five calves were placed in each pen; all calves remained in the same pen from d 1 of life until weaning at $60 \mathrm{~d}$ of life.
All heifer calves were fed unrestricted, acidified, nonsalable milk. Acidification was performed inside a sealed stainless-steel tank where the nonsalable cold milk $\left(5^{\circ} \mathrm{C}\right)$ was constantly mixed with organic acid until a $\mathrm{pH}$ of 4.5 was reached. Acidified milk was kept for $72 \mathrm{~h}$ inside the stainless-steel tank after the acidification process was finished. Milk was then directed to a smaller stainless-steel tank responsible for heating $\left(18.5^{\circ} \mathrm{C}\right)$ and supplying each pen feeder with constant acidified milk. Each feeder consisted of 6 nipples for a pen of 25 calves. All calves in this study were weaned by reducing the time of milk availability starting on $\mathrm{d}$ 55; a gradual reduction of time was performed for $5 \mathrm{~d}$ until the complete absence of milk at $60 \mathrm{~d}$ of life.

\section{Lung Ultrasonography}

One member of the research team was responsible for performing lung ultrasonography on all calves at $60 \mathrm{~d}$ of life. A structure was built using stainless-steel bars in a gate-like "U" layout (3 parts); the structure was fixed inside each pen $(1.5 \mathrm{~m} \times 0.75 \mathrm{~m})$ by latching one end to the gate pen, which allowed for single calf isolation where ultrasonographic exams were performed. This structure was washed and used for the next pen by the time of thoracic ultrasound examination. Thoracic ultrasound examinations were carried out using an Ibex-pro device with a $6.2-\mathrm{MHz}$ linear transducer (E.I. Medical Imaging, Loveland, CO). Examination of the lung areas was performed by screening dorsal to ventral intercostal spaces from the right 2 nd through 10th and left 3rd through 9th intercostal spaces. The first intercostal space of the right side was not included in the examination because the examiner could not consistently reach the 1st intercostal space for all the calves examined. Calves were not shaved in any area on the thorax; to achieve better contact and imaging quality, $70 \%$ isopropyl alcohol was applied to the haired areas under examination.

The scoring procedure used in this study was an adaptation from Ollivett et al. (2011). Thoracic ultrasound was performed on each hemithorax for all calves and a 2-point scale assigned: no lung consolidation (NC) or with any detectable lung consolidation (LC). Animals received one score based on the combined exam of the right and left thoracic area. Each exam required approximately $5 \mathrm{~min}$ per calf. Heifers were classified as NC if no abnormalities were detected on thoracic ultrasound, that is, well-ventilated peripheral lung tissue (hyperechoic line with reverberation artifact) or comet-tail artifacts observed in one or multiple lobes (hyperechoic vertical lines originating from the aerated lung surface). Heifers were classified as LC if a detect- 

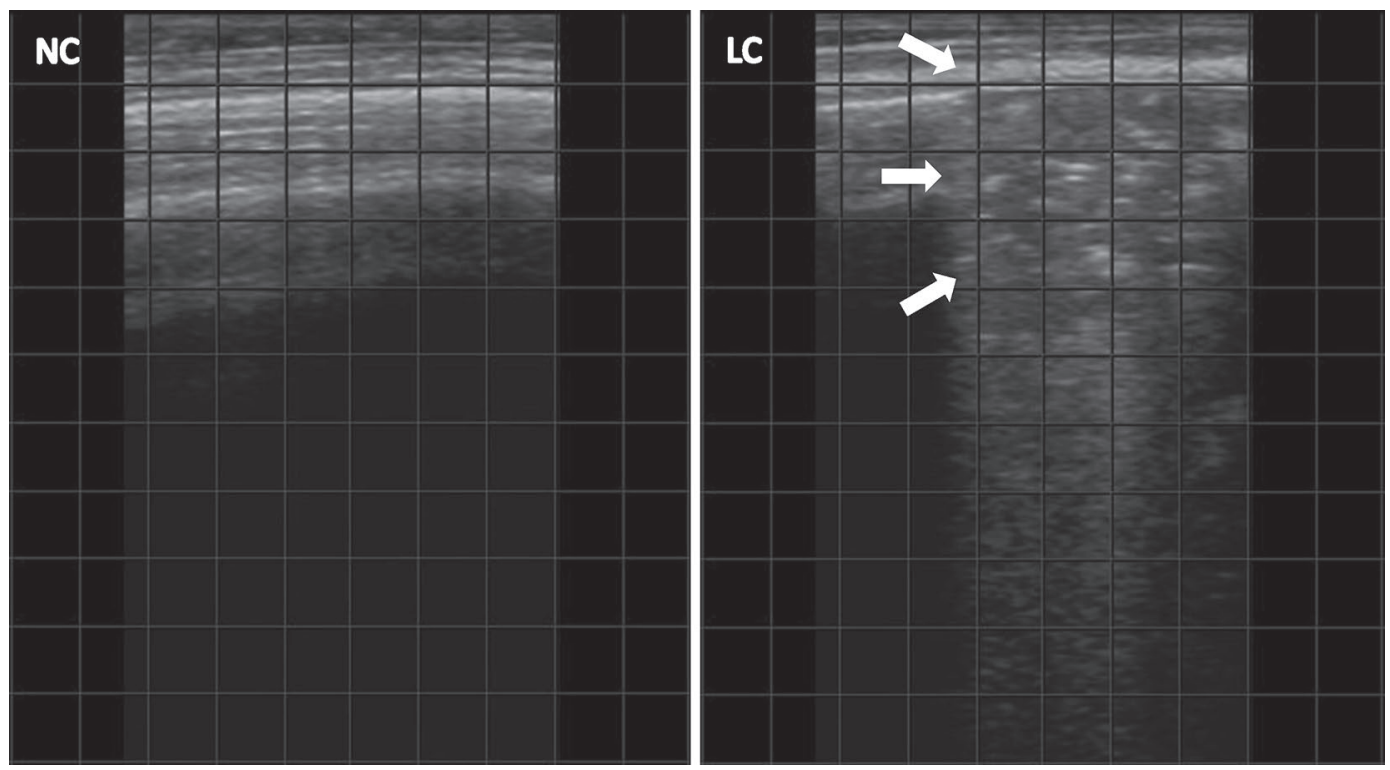

Figure 1. Ultrasonographic evidence of heifers with no consolidation (NC; well-ventilated peripheral lung tissue represented by hyperechoic line with reverberation artifact or with comet-tail artifacts observed in one or multiple lobes represented by hyperechoic vertical lines originating from the aerated lung surface) and heifers with detectable consolidation (LC; any detectable consolidation represented by a heterogeneous hypoechoic area without the clear line of the pleural surface in one or more lung lobes). Each square is $1 \mathrm{~cm}^{2}$.

able consolidation was observed, meaning any size consolidation (heterogeneous hypoechoic area without the clear line of the pleural surface) detected in one or more lung lobes (Figure 1).

\section{Postweaning}

After thoracic ultrasound, heifers were moved to a postweaning pen. Weaned heifer pens were fed TMR daily to maintain a weight gain of approximately 0.9 $\mathrm{kg} / \mathrm{d}$ (NRC, 2001). Vaccination against infectious bovine rhinotracheitis virus, bovine viral diarrhea virus (types 1 and 2), bovine respiratory syncytial virus, parainfluenza-3 virus, and clostridial diseases was performed at 3 mo of age (Vista $5 \mathrm{SQ}$ and Covexin 8, Merck Animal Health, Elkhorn, NE). Heifers were moved weekly to breeding pens around $350 \mathrm{~d}$ of life. Once in the breeding pens, heifers were allowed $30 \mathrm{~d}$ of AI upon estrus detection before receiving an injection of prostaglandin followed by estrus detection. Heifers not detected in estrus were given a repeat prostaglandin injection every 2 wk until $550 \mathrm{~d}$ of life. Pregnancy diagnoses were performed by veterinarians for inseminated animals between 35 and 41 d post-AI. Pregnancy diagnoses were confirmed by a recheck performed between 61 and $74 \mathrm{~d}$ post-AI. Starting at approximately $240 \mathrm{~d}$ of gestation, heifers were moved weekly from the breeding pens to a close-up pen where animals were more closely monitored by farm employees. Pregnant animals detected in stage 1 or 2 of parturition were moved to the maternity pen. After calving, primiparous cows were milked at the maternity pen and then moved to a fresh cow pen within $6 \mathrm{~h}$ of first milking. Primiparous fresh cows were milked 3 times per day in a 100-stall rotary parlor. All lactating animals were offered TMR formulated to meet or exceed the NRC (2001) nutrient requirements for lactating Holstein cows weighing 650 $\mathrm{kg}$ and producing $45 \mathrm{~kg}$ of $3.5 \%$ FCM.

A voluntary waiting period of $50 \mathrm{~d}$ was used for primiparous cows. The reproductive management for first lactation cows used a combination of Presynch, Ovsynch, Resynch, and detection of estrus, with approximately $30 \%$ of cows bred via timed AI and the remainder bred after detection of estrus solely by activity monitors (Alpro, DeLaval, Kansas City, MO). Briefly, the protocol for first insemination used 2 injections of prostaglandin administered $14 \mathrm{~d}$ apart for presynchronization, followed by the Ovsynch-56 protocol $7 \mathrm{~d}$ later to facilitate timed AI. Animals detected in estrus after the second prostaglandin injection through the start of the Ovsynch protocol were inseminated. Pregnancy diagnoses for primiparous cows were performed for inseminated animals between 35 and $41 \mathrm{~d}$ post-AI and confirmed by a recheck performed between 61 and 67 d post-AI.

Animals were followed until the first 90 DIM. Postpartum diseases were diagnosed by trained farm employees; retained placenta was noted for animals that retained fetal membranes $>24 \mathrm{~h}$ after parturition, metritis was recorded for animals with fetid watery red- 
brown uterine discharge with or without fever within $21 \mathrm{~d}$ postpartum, and clinical mastitis was noted for animals with at least one quarter presenting abnormal milk. Treatments were performed according to farm protocols.

\section{Statistical Analyses}

A priori sample size calculation was performed based on a $10 \%$ difference in survival rate between heifers without lung consolidation (0.95) and heifers with lung consolidation (0.85). Expecting that lung consolidation would be detected by the end of the weaning period in 1 out of 10 heifers, with a probability of type I error of 0.05 and a power of 0.80 , a total of 600 heifers were enrolled in this study.

The data retrieved from the farm's computer software (DairyComp 305 Valley Agricultural Software, Tulare, CA) included age at first breeding, age at conception (defined after pregnancy diagnosis confirmation at approximately $60 \mathrm{~d}$ of gestation, back calculated as the number of days from birth to the day of conception), removal from herd (including death and animals that were sold), pregnancy risk to first service (percent of animals pregnant to the first AI), pregnancy length, age at first parturition, abortions (gestation length $<260$ d), twins, stillbirth, assisted or nonassisted parturition, and offspring birth weight (measured before colostrum feeding by farm employees using a dedicated scale; Waypig Digital 500, Raytec, Ephrata, PA). First lactation data regarding average weekly milk production were collected until 90 DIM. Data regarding postpartum diseases (retained placenta, metritis, and clinical mastitis) were also retrieved from farm records.

Descriptive statistics regarding differences between lung score category ( $\mathrm{NC}$ vs. LC) and the normally distributed continuous variables (age at first breeding, age at first calving, gestation length, and offspring weight at birth) were performed using 2 -sided $t$-tests. Chisquared tests were used to compare the risk of pregnancy to first service, abortion, stillbirth, twinning, and assisted parturition between lung consolidation groups (TTEST and FREQ procedures in SAS; version 9.4, SAS Institute Inc., Cary, NC).

To assess the association of lung score with survival and reproductive performance, 2 similar Kaplan-Meier time-to-event models were fitted using the LIFETEST procedure in SAS. For the culling analysis, animals were censored on the day of herd removal regardless of reason (animals that died or were sold) or rightcensored on the day of parturition. For the reproductive performance analysis $(\mathrm{n}=601)$, heifers were censored at age at conception or right-censored at time of herd removal for animals that were never confirmed preg- nant. The last pregnant animal calved at $840 \mathrm{~d}$ of life, which was then considered the end of the evaluation period. Because no animals were removed from the herd after $550 \mathrm{~d}$, the time-to-event was arbitrary limited to 740 d of life. Kaplan-Meier plots were created using MedCalc (Version 16.4.3, MedCalc Software, BVBA, Ostend, Belgium).

For animals entering the milking herd $(\mathrm{n}=565)$, differences in the number of animals in each cohort based on lung consolidation, proportion of primiparous animals diagnosed pregnant at first service $(\mathrm{n}=546)$, incidence of retained placenta $(\mathrm{n}=565)$, metritis $(\mathrm{n}$ $=565)$, and clinical mastitis $(\mathrm{n}=565)$ tests were performed using the FREQ (chi-squared test) and TTEST (2-sided $t$-test) procedures in SAS. Additionally, 2 similar Kaplan-Meier models were used to evaluate the association of lung ultrasonography performed at $60 \mathrm{~d}$ of life with primiparous reproductive performance $(\mathrm{n}=$ $546)$ and survival for the first 90 DIM $(\mathrm{n}=565)$.

Weekly milk production data were collected for the first 90 DIM from all the cows entering the milking herd $(\mathrm{n}=565)$. Average weekly milk production for the first 90 DIM was assessed using repeated-measures ANOVA with the MIXED procedure of SAS and an autoregressive covariance structure. Animal within the lung consolidation group was treated as a random effect, and thoracic ultrasound score ( $\mathrm{NC}$ or LC) and week in milk (1 to 12 ) were treated as covariates. Least squares means and standard errors were estimated and reported. Model fit was assessed by visually evaluating the distribution plot of the studentized residuals. For this model, Bonferroni correction for multiple comparisons was used. Statistical significance was declared at $P \leq 0.05$ and statistical tendencies at $0.05<P \leq 0.10$.

\section{RESULTS}

A total of 613 heifer calves were enrolled in the study, with $489(79.8 \%)$ classified as NC and $124(20.2 \%)$ classified as LC. From 60 to 350 d of life, $1.6 \%$ of animals in the LC group and $2.0 \%$ of animals in the NC group were removed from the herd $(P=0.74)$. Thus, the total number of animals remaining in the study at $350 \mathrm{~d}$ of life was 601 .

For 601 animals entering the reproduction phase, survival was evaluated from $350 \mathrm{~d}$ of life to age at calving (Figure 2). The proportion of animals culled in the LC cohort was 15.6 and $3.5 \%$ for the NC cohort during this period. A higher hazard of death was observed in LC than NC heifers [hazard ratio $(\mathbf{H R})=4.7,95 \%$ $\mathrm{CI}=2.1$ to $10.7 ; P<0.001]$. Additionally, LC heifers had a lower hazard of pregnancy when compared with $\mathrm{NC}$ heifers $(\mathrm{HR}=0.7,95 \% \mathrm{CI}=0.6$ to $0.8 ; P=0.006$; Figure 3$)$. No differences in age at first breeding were 
Table 1. Age at first breeding; age at first calving; gestation length; offspring weight; and percentage of pregnancy to first service, abortion, stillbirth, twins, and assisted parturition when thoracic ultrasonography was performed at $60 \mathrm{~d}$ of life and heifers were classified as having no lung consolidation (only clear pleural surfaces or comet tails were observed) or lung consolidation (any detectable consolidation in one or more lung lobes)

\begin{tabular}{lccc}
\hline Item & $\begin{array}{c}\text { No lung consolidation } \\
\text { [Mean (SE)] }\end{array}$ & $\begin{array}{c}\text { Lung consolidation } \\
\text { [Mean (SE)] }\end{array}$ & $P$-value \\
\hline Age at first breeding (d) & $386.7(0.6)$ & $386.0(1.0)$ & 0.42 \\
Age at first calving (d) & $679.8(1.4)$ & $687.4(2.0)$ & 0.04 \\
Gestation length (d) & $277.6(0.2)$ & $277.2(0.5)$ & 0.48 \\
Offspring weight (kg) & $37.5(0.2)$ & $37.4(0.5)$ & 0.76 \\
Pregnancy to first service (\%) & 62.0 & 52.5 & 0.06 \\
Abortion (\%) & 2.2 & 2.9 & 0.63 \\
Stillbirth (\%) & 6.9 & 9.1 & 0.12 \\
Twins (\%) & 2.7 & 2.5 & 0.69 \\
Assisted parturition (\%) & 17.3 & 20.3 & 0.35 \\
\hline
\end{tabular}

observed between the 2 cohorts. However, age at first calving was significantly lower in NC heifers than LC heifers $(P=0.04$, Table 1$)$. A tendency for lower pregnancy risk to first service was observed in LC heifers (52.5\%) compared with NC heifers $(62.0 \% ; P=0.06)$.

From 601 heifers that entered the reproduction phase at $350 \mathrm{~d}$ of life, 565 pregnant heifers calved and entered the milking herd. No differences were observed for any of the other variables: gestation length, stillborn, twins,

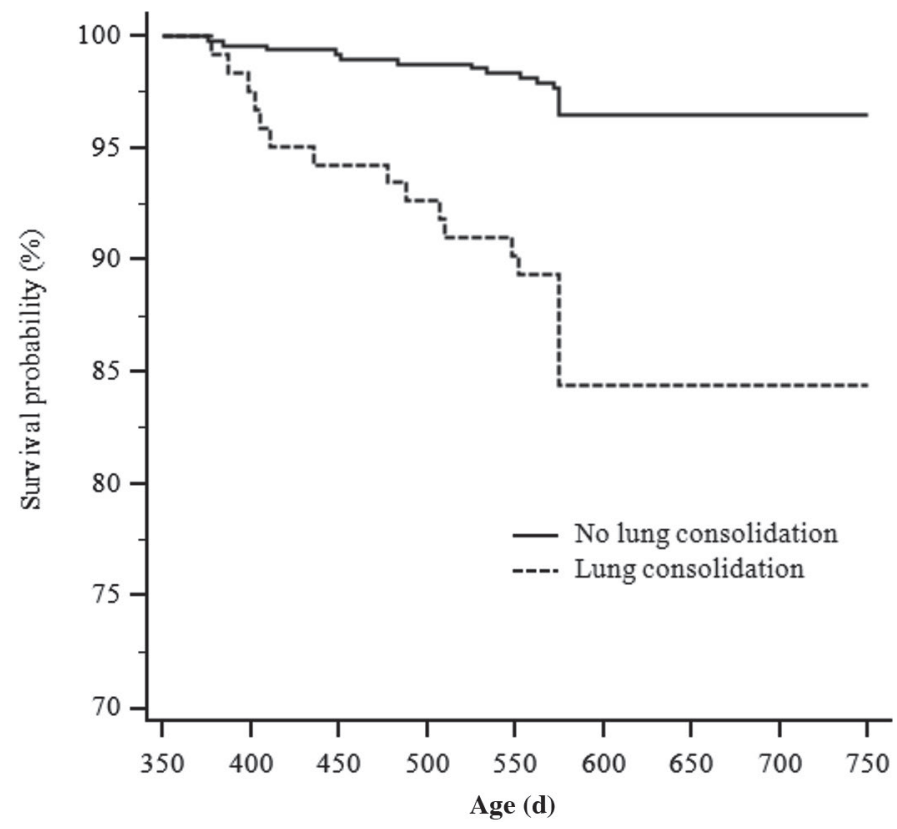

Figure 2. Kaplan-Meier analysis of time to culling in 601 nulliparous Holstein heifers that underwent lung ultrasonography evaluation at $60 \mathrm{~d}$ of life. Ultrasonographic lung score of each thoracic ultrasound was evaluated on a 2-point scale defined as no lung consolidation (only clear pleural surfaces or comet tails were observed, solid line) or lung consolidation (any detectable consolidation in one or more lung lobes, dashed line). Heifers with lung consolidation had a higher hazard of culling compared with heifers without lung consolidation (hazard ratio $=4.7,95 \% \mathrm{CI}=2.1$ to $10.7 ; P<0.001)$. abortions, assisted parturition, and offspring birth weight (Table 1).

No differences in survival were observed for primiparous cows between $\mathrm{LC}$ and $\mathrm{NC}$ animals between calving and the first 90 DIM. The hazard of culling was 1.0 (95\% CI $=0.5$ to $2.1 ; P=0.93$ ). Moreover, only 546 primiparous cows that entered the milking herd were

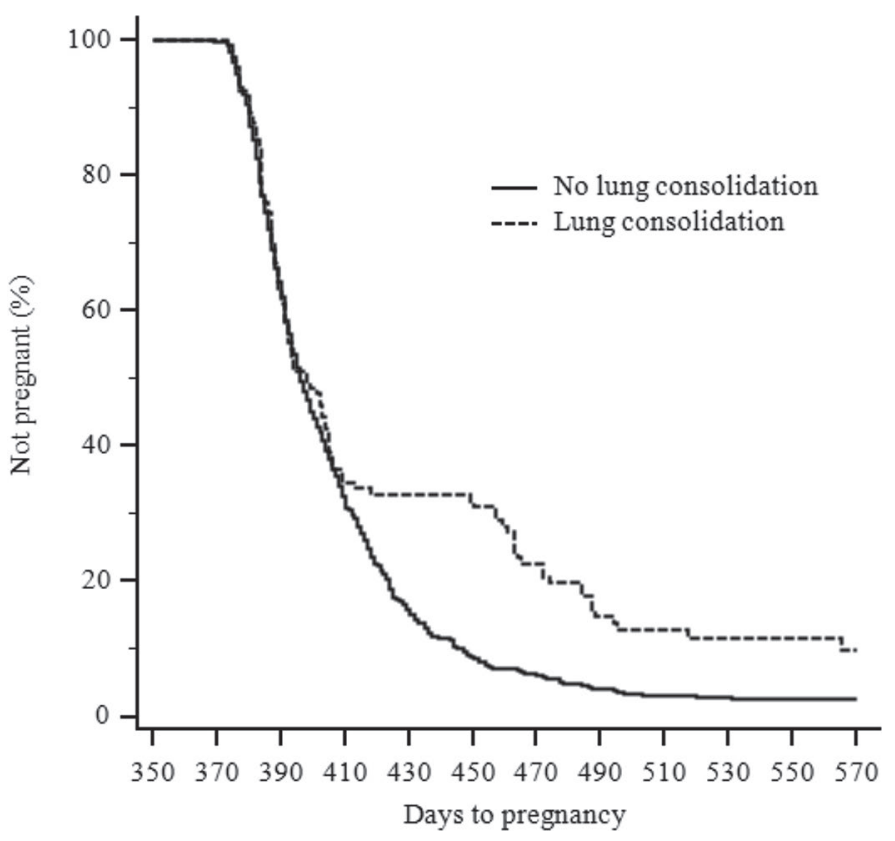

Figure 3. Kaplan-Meier analysis of time to pregnancy in 601 nulliparous Holstein heifers that underwent lung ultrasonography evaluation at $60 \mathrm{~d}$ of life. Ultrasonographic lung score of each thoracic ultrasound was evaluated on a 2-point scale defined as no lung consolidation (only clear pleural surfaces or comet tails were observed, solid line) or lung consolidation (any detectable consolidation in one or more lung lobes, dashed line). Animals were followed from $350 \mathrm{~d}$ of life until age of confirmed pregnancy or removal from the herd. Heifers with lung consolidation had a lower hazard of being pregnant compared with heifers without lung consolidation (hazard ratio $=0.7$, $95 \% \mathrm{CI}=0.6$ to $0.8 ; P=0.006)$. 
alive at 50 DIM (50 d of voluntary waiting period). No differences in reproductive performance were observed between LC and NC animals; the hazard of pregnancy was $1.0(95 \% \mathrm{CI}=0.7$ to $1.4 ; P=0.81)$.

No differences between incidences of postpartum diseases or pregnancy to first service were observed for primiparous cows. For 565 pregnant heifers that calved, no differences were found regarding the incidence of retained placenta $(P=0.15)$ between $\mathrm{LC}(6.0 \%)$ and NC $(2.7 \%)$, incidence of metritis $(P=0.74)$ between LC $(32.2 \%)$ and $\mathrm{NC}(30.6 \%)$, and incidence of clinical mastitis $(P=0.90)$ between LC $(6.1 \%)$ and NC $(5.8 \%)$. For 546 primiparous cows, no difference between pregnancy to first service was observed $(P=0.38)$ between LC $(30.2 \%)$ and NC (26.8\%).

First lactation average weekly milk production data were collected. No differences were observed for the first 12 wk of milk production between animals diagnosed with or without lung consolidation as heifers $(P$ $=0.73)$.

\section{DISCUSSION}

To our knowledge, this is the first study evaluating the association of one-time thoracic ultrasound in replacement Holstein heifer calves and later performance. Although this is a single herd study, 613 heifer calves underwent thoracic ultrasound at $60 \mathrm{~d}$ of life in which 546 of these calves continued to be followed through 90 DIM. Heifers detected with lung consolidation at $60 \mathrm{~d}$ of life had a higher age at first calving, a higher hazard of death, and a lower hazard of pregnancy than heifers without lung consolidation. Additionally, a tendency for lower pregnancy to first service was reported for heifers with lung consolidation when compared with heifers without lung lesions. However, the effect of a one-time ultrasonographic evaluation at $60 \mathrm{~d}$ of life seemed to have detrimental effects only before animals entered their first lactation. No differences were observed for postpartum disease incidences (retained placenta, metritis, and mastitis), reproductive performance, or survival in the first 90 DIM between animals with lung consolidation or without consolidation at $60 \mathrm{~d}$ of life.

In a recently published study, 240 Jersey heifers had a single thoracic ultrasound at $96 \pm 6 \mathrm{~d}$ of life and were followed until age at calving or removal from the herd (Adams and Buczinski, 2016). Calves with at least one site of consolidation $(\geq 6 \mathrm{~cm})$, abscessation within the lung parenchyma, or significant pleural effusion $(>1 \mathrm{~cm})$ had a higher chance of being removed from the herd. Interestingly, the survival of Jersey heifers with limited extent of lung consolidation (consolidation between 1 and $6 \mathrm{~cm}$ ) was no different than heifers with no consolidation. In our study, heifers with no lung consolidation on thoracic ultrasound had better survival from $350 \mathrm{~d}$ of life to calving than calves showing any consolidation. The scoring system generated by thoracic ultrasound in our study was simplified even further than others have proposed (Ollivett et al., 2011; Adams and Buczinski, 2016). Thoracic ultrasonography was performed in a stationary unit that allowed the examination of the right 2nd through 10th and left 3rd through 9th intercostal spaces. In the present study, researchers were unable to include the ultrasound data from the 1st intercostal space; this certainly decreases the ability of researchers to detect possible consolidations present in the cranial aspect of the right cranial lobe, which can be inspected at the 1st and 2 nd intercostal space on the right hemithorax (Ollivett et al., 2013).

Our observed outcomes for calves with lung consolidation at $60 \mathrm{~d}$ of life are in agreement with the deleterious effect of BRD detected before $90 \mathrm{~d}$ of age, specifically delayed age at first calving (Correa et al., 1988) and increased risk of death (Stanton et al., 2012). Additionally, poorer reproductive performance was reported for BRD-treated calves before $60 \mathrm{~d}$ of life (Bach, 2011; Stanton et al., 2012). In the current study, because of the known subjectivity of BRD detection (Sivula et al., 1996), no attempt was made to retrieve farm data on BRD treatments. Two very useful charts are widely used as an on-farm tool to diagnose BRD (McGuirk, 2008; Love et al., 2014). Although chartdriven systems are a good tool in helping caretakers to diagnose cases of BRD, they are still highly dependent on the ability of the caretaker to observe clinical signs; misclassification could lead to unnecessary use of antimicrobials and misleading data regarding BRD.

In the current study, Holstein heifers without lung consolidation at $60 \mathrm{~d}$ of life had $62.0 \%$ pregnancy to first service which is in agreement with data published elsewhere for Holstein heifers in United States (Ettema and Santos, 2004). However, a tendency of lower pregnancy rate at first service $(52.5 \%)$ was observed for heifers with lung consolidation. The reproductive performance results presented for nulliparous heifers might be attributed to a lower weight gain during the first $6 \mathrm{mo}$ as weight gain has previously been related to lung lesions in feedlot steers (Wittum et al., 1996). Delayed age at first calving and lower pregnancy risk at first service are frequently associated with suboptimal growth rates before 6 mo of age (Brickell et al., 2009). However, no differences in age at first breeding between heifers with or without lung consolidation were observed in this study.

The thoracic ultrasonography technique used in our study can be performed in a relatively short time using a conventional linear probe and ultrasound. Although no antemortem calf-side gold standard tool to diagnose 
BRD exists, implementation of thoracic ultrasound should be considered by veterinarians in replacement heifer facilities; this practice can be used to detect heifers with higher risks of replacement failure. Different management practices can then be assigned to at-risk groups of heifers as needed, adjusting growth rates, pathogen screening, and selective use of antimicrobials.

\section{CONCLUSIONS}

As proposed by others that performed thoracic ultrasonography, the use of a calf-side tool to improve heifers management should be further investigated using a larger number of animals and in different preweaning rearing systems. Although no detrimental effects of lung lesions at $60 \mathrm{~d}$ of life were observed for primiparous cows during the first 90 DIM into the first lactation, we found significant effects for nulliparous heifers through a decrease in reproductive performance and an increase in culling risk.

\section{REFERENCES}

Adams, E. A., and S. Buczinski. 2016. Short communication: Ultrasonographic assessment of lung consolidation postweaning and survival to the first lactation in dairy heifers. J. Dairy Sci. 99:14651470. 10.3168 /jds.2015-10260.

Bach, A. 2011. Associations between several aspects of heifer development and dairy cow survivability to second lactation. J. Dairy Sci. 94:1052-1057. 10.3168/jds.2010-3633.

Brickell, J. S., N. Bourne, M. M. McGowan, and D. C. Wathes. 2009. Effect of growth and development during the rearing period on the subsequent fertility of nulliparous Holstein-Friesian heifers. Theriogenology 72:408-416. 10.1016/j.theriogenology.2009.03.015.

Buczinski, S., G. Forté, and A. M. Bélanger. 2013. Short communication: Ultrasonographic assessment of the thorax as a fast technique to assess pulmonary lesions in dairy calves with bovine respiratory disease. J. Dairy Sci. 96:4523-4528. 10.3168/jds.2013-6577.

Buczinski, S., G. Forté, D. Francoz, and A. M. Bélanger. 2014. Comparison of thoracic auscultation, clinical score, and ultrasonography as indicators of bovine respiratory disease in preweaned dairy calves. J. Vet. Intern. Med. 28:234-242. https://doi.org/10.1111/ jvim. 12251.

Correa, M. T., C. R. Curtis, H. N. Erb, and M. E. White. 1988. Effect of calfhood morbidity on age at first calving in New York Holstein herds. Prev. Vet. Med. 6:253-262. 10.1016/0167-5877(88)90037-2.

Ettema, J. F., and J. E. Santos. 2004. Impact of age at calving on lactation, reproduction, health, and income in first-parity Holsteins on commercial farms. J. Dairy Sci. 87:2730-2742. https://doi. org/10.3168/jds.S0022-0302(04)73400-1.
Jung, C., and H. Bostedt. 2004. Thoracic ultrasonography technique in newborn calves and description of normal and pathological findings. Vet. Radiol. Ultrasound 45:331-335. https://doi. org/10.1111/j.1740-8261.2004.04063.x.

Love, W. J., T. W. Lehenbauer, P. H. Kass, A. L. Van Eenennaam, and S. S. Aly. 2014. Development of a novel clinical scoring system for on-farm diagnosis of bovine respiratory disease in pre-weaned dairy calves. PeerJ 2:e238. https://doi.org/10.7717/peerj.238.

McGuirk, S. M. 2008. Disease management of dairy calves and heifers. Vet. Clin. North Am. Food Anim. Pract. 24:139-153. https://doi. org/10.1016/j.cvfa.2007.10.003.

NRC. 2001. Nutrient Requirements of Dairy Cattle. 7th rev. Natl. Acad. Press, Washington, DC.

Ollivett, T. L., A. J. Burton, R. C. Bicalho, and D. V. Nydam. 2011. Use of rapid US for detection of subclinical and clinical pneumonia in dairy calves. In Proceedings American Association of Bovine Practitioner, Vol. 44. Stillwater, OK. 2011:148.

Ollivett, T., J. Hewson, R. Schubotz, and J. Caswell. 2013. Ultrasonographic progression of lung consolidation after experimental infection with Mannheimia haemolytica in Holstein calves. Page 673 in Proc. American Veterinary Internal Medicine Forum, Seattle, WA. J. Vet. Intern. Med., Malden, MA.

Ollivett, T. L., J. L. Caswell, D. V. Nydam, T. Duffield, K. E. Leslie, J. Hewson, and D. Kelton. 2015. Thoracic ultrasonography and bronchoalveolar lavage fluid analysis in Holstein calves with subclinical lung lesions. J. Vet. Intern. Med. 29:1728-1734. https:// doi.org/10.1111/jvim.13605.

Rabeling, B., J. Rehage, D. Dopfer, and H. Scholz. 1998. Ultrasonographic findings in calves with respiratory disease. Vet. Rec. 143:468-471.

Schneider, M. J., R. G. Tait Jr., W. D. Busby, and J. M. Reecy. 2009. An evaluation of bovine respiratory disease complex in feedlot cattle: Impact on performance and carcass traits using treatment records and lung lesion scores. J. Anim. Sci. 87:1821-1827. https:// doi.org/10.2527/jas.2008-1283.

Sivula, N. J., T. R. Ames, W. E. Marsh, and R. E. Werdin. 1996. Descriptive epidemiology of morbidity and mortality in Minnesota dairy heifer calves. Prev. Vet. Med. 27:155-171. https://doi. org/10.1016/0167-5877(95)01000-9.

Stanton, A. L., D. F. Kelton, S. J. LeBlanc, J. Wormuth, and K. E. Leslie. 2012. The effect of respiratory disease and a preventative antibiotic treatment on growth, survival, age at first calving, and milk production of dairy heifers. J. Dairy Sci. 95:4950-4960. https://doi.org/10.3168/jds.2011-5067.

Thompson, P. N., A. Stone, and W. A. Schultheiss. 2006. Use of treatment records and lung lesion scoring to estimate the effect of respiratory disease on growth during early and late finishing periods in South African feedlot cattle. J. Anim. Sci. 84:488-498.

USDA. 2012. Dairy Heifer Raiser, 2011. N613.1012. USDA-APHIS-VS, CEAH, National Animal Health Monitoring System (NAHMS), Fort Collins, CO.

Wittum, T. E., N. E. Woollen, L. J. Perino, and E. T. Littledike. 1996. Relationships among treatment for respiratory tract disease, pulmonary lesions evident at slaughter, and rate of weight gain in feedlot cattle. J. Am. Vet. Med. Assoc. 209:814-818. 